\title{
A Full Systematic Review on the Effects of Cognitive Behavioural Therapy for Mental Health Symptoms in Child Refugees
}

\author{
Katie Lawton ${ }^{1}$ (D) Angela Spencer ${ }^{2}$
}

Accepted: 22 January 2021 / Published online: 15 February 2021

(c) The Author(s) 2021

\begin{abstract}
Global conflict in 2019 created record numbers of displaced children. These children have experienced multiple traumas and subsequently suffer high levels of mental health symptoms. Cognitive-behavioural therapy (CBT) is commonly used for post-traumatic stress disorder (PTSD), depression and anxiety, however the current evidence-base of CBT in child refugees is sparse, with mixed results. This study aimed to assess the effects of CBT on symptoms of PTSD, depression and anxiety in child refugees/AS. Ethics were reviewed and granted by the University of Manchester ethics committee. Medline, Embase, Cochrane, PsycINFO and CINAHL were systematically searched. Studies were included if CBT was delivered to refugee/ AS children with pre and post-intervention measures of symptoms. Sixteen studies fulfilled criteria. In all studies, mental health symptom scores post-intervention had reduced, suggesting an improvement in mental health following CBT. This reduction was statistically significant in twelve studies $(\mathrm{p}<0.001-0.5)$, clinically significant in eight studies and maintained at follow-up periods. No adverse effects of CBT were identified. This is the first systematic review to focus solely on CBT in child refugee populations, with unanimously positive results. Its use is cautiously recommended, however the need for more methodologically rigorous studies in this population is highlighted.
\end{abstract}

Keywords Refugee $\cdot$ Asylum-seeker $\cdot$ Child $\cdot$ Cognitive-behavioural therapy $\cdot$ Mental health $\cdot$ Psychological therapy

\section{Introduction}

\section{Background}

Levels of displacement experienced globally in 2019 were the highest ever on record, with an estimated 70.8 million people forced to flee their homes due to conflict and persecution (United Nations High Commissioner for Refugees (1). This has created more than 29 million refugees and asylum seekers worldwide, half of whom are under the age of 18 (1).

The 1951 United Nations Convention Relating to the Status of Refugees defined a refugee as.

"A person who owing to a well-founded fear of being persecuted for reasons of race, religion, nationality, membership of a particular social group or political opinion, is outside

Katie Lawton

Klawton3@doctors.org.uk

1 St Helens and Knowsley Teaching Hospitals NHS Trust, 474, Kings Road, Stretford, Manchester M32 8QW, UK

2 University of Manchester, Oxford Road, Manchester M13 9PL, UK the country of his nationality and is unable or, owing to such fear, is unwilling to avail himself of the protection of that country; or who, not having a nationality and being outside the country of his former habitual residence as a result of such events, is unable or, owing to such fear, is unwilling to return to it." (2). An asylum seeker (AS) is "a person who has left their country of origin and formally applied for asylum in another country but whose application has not yet been concluded" (3).

Child refugees are frequently subject to multiple stressors and traumas (4), which are conventionally described in terms of "phases" of the journey; pre-flight, flight and resettlement. Pre-flight includes the initial traumas they were escaping from, and the upheaval of moving. Flight includes unsafe transit and living in transitional placements such as refugee camps. Resettlement stressors can just be as traumatising as the initial stressors for children (5), and include time spent in detention centres, uncertainty about the future, poverty and cultural shock (6). Subsequently up to $80 \%$ of refugee children have depression, PTSD and anxiety (7-13). This rate is more than twice that of U.S. adolescents (14). Furthermore, refugee children with mental health symptoms are at greater 
risk of physical health symptoms (15), poorer educational attainment (16) and correlate with acculturalisation issues (17). Prompt identification of such mental health problems helps to reduce self-harm and suicide (18).

Despite their high levels of mental health morbidity, refugee children are under-represented in mental health services (19), with $49 \%$ of mental health symptoms unmet (20). This is despite evidence that treatment can reduce the mental health symptoms of refugees (21). Research has highlighted linguistic and socio-cultural barriers, difficulties navigating services, and financial and transport constraints as barriers to service access (22-25).

Cognitive-behavioural therapy (CBT) is a psychological therapy commonly used in the treatment of depression, PTSD and anxiety (26). The Royal College of Psychiatrists define CBT as a verbal therapy which considers how an individual appraises a situation, how these thoughts affect their emotions and behaviour and subsequently how the behaviour and emotions feed-back into cognitions (27). In CBT the therapist and client work collaboratively in changing the client's maladaptive thinking and behavioural patterns, releasing them from vicious cycles of negativity and learning practical skills to move forwards. Trauma-focused CBT is a subset of CBT that is specifically adapted for PTSD symptoms.

CBT is considered one of the most efficacious and evidence-based interventions for PTSD in traumatised nonrefugee children, particularly trauma-focused CBT (28-30). CBT randomised controlled trials (RCTs) conducted on wartraumatised non-displaced children demonstrated successful reductions in PTSD, anxiety and depression symptoms, with effect sizes ranging from medium to large (Cohen's $\mathrm{d}=0.76-1.24)$, (31-33). Morina et al. (2017) conducted a meta-analysis of CBT on children living within war and reported pre/post CBT medium effect sizes for PTSD symptoms (Hedge's $g=1.15$ ), and small effect sizes of CBT on depressive symptoms (Hedge's $g=0.25-0.3$ ) (34).

Logically it follows that CBT is an appropriate treatment option for refugee children. Several systematic reviews have compared differing psychological therapies for this population. Tyrer and Fazel (2014) included eight primary CBT studies in their review of fourteen psychological therapies and found that mental health symptoms of depression, PTSD and anxiety were significantly reduced in all studies, with medium to large Cohen's d effect sizes where calculated $(d=0.64-0.93)$ (35). Sullivan and Simonson (2016) included four primary CBT studies in their systematic review of thirteen psychological therapies and found that mental health symptoms were significantly reduced in all four studies, although no effect sizes were given (36). Both studies noted that CBT interventions showed the most consistent outcomes and highlighted its feasibility in school settings.
In contrast, Nocon et al. (2017) reviewed school-based therapies for depression and anxiety in child refugees and found small or insignificant effect sizes (37). However, the authors commented that "CBT showed the most promising results that need further replication" (37). All three systematic reviews called for further research to clarify findings relating to CBT.

This systematic review answers those calls and is the first to have a narrow research focus on the effectiveness of CBT in child refugee populations.

\section{Objectives}

Objective 1.) To assess the effects of CBT on PTSD, anxiety and depression in child refugees/AS.

Objective 2.) To assess the accessibility and acceptability of CBT for child refugees/AS.

\section{Methods}

\section{Search Strategy}

Review methods were conducted in accordance with the Preferred Reporting Items for Systematic Reviews and MetaAnalyses (PRISMA) guidelines (38).

Ethics were reviewed and approved from the University of Manchester ethics review committee in September 2018. The review was registered with PROSPERO in January 2019.

\section{Criteria for Inclusion of Studies}

\section{Population}

Participants must be refugees/AS aged 2-18.

\section{Intervention}

Studies were included if CBT was delivered as a treatment modality, in all intervention settings and delivered by any individual. The description of the CBT used needed to align with the Royal College of sec3Psychiatry's definition of CBT described in the introduction Sect. (57), however all subtypes of CBT were included. Studies which used CBT in combination with other treatment methods were excluded as it would not be possible to extract the outcomes of CBT alone. Only studies which delivered a programme of CBT were included, rather than a singular session. The CBT could be delivered individually or as group-therapy. 


\section{Comparison}

Studies were included if they involved either a within-subject or a between-subjects comparison of PTSD, anxiety or depression. Equivalence studies were included if it was possible to extract the pre and post-outcome measures for the population receiving $\mathrm{CBT}$.

\section{Outcomes}

The primary outcome of interest for objective one was any change in PTSD, anxiety or depression pre and post-CBT, measured using a validated scale. Any adverse effects were also recorded.

The primary outcome of objective two was any recorded expressions of acceptability and feasibility made by the children or those delivering the intervention. Due to time constraints, only studies included for objective one will be analysed for these.

\section{Study Types}

Only primary research studies were included. This incorporated randomised controlled trials and observational studies with an interventional component and measurable outcomes. Preliminary database searches have confirmed a paucity of large-scale studies on this topic, and therefore case-series and case-studies were also included. Only studies reported in the English language were included.

\section{Search Terms}

The search strategy was developed in consultation with an academic librarian, and included key terms and synonyms associated with (1) adolescent/child, AND (2) refugees/asylum seekers/ "displaced by war", AND (3) cognitive therapy/ psychological adaptation (see Appendix A for full search strategies used) (Fig. 1)

In April 2020 five data-bases were systematically searched: Medline, Embase, Cochrane, PsycINFO and CINAHL. Hand searching was conducted to identify any key grey literature in the area.

\section{Results}

The details of literature search and study selection procedure are outlined in the PRISMA flow diagram (Fig. 2). A total of 579 studies were identified via the electronic database search, and an additional 28 articles via hand-searching and the snowballing technique, whereby studies of interest were identified from the reference list of highly relevant
Fig. 1 Inclusion and Exclusion Criteria

\begin{tabular}{|c|c|}
\hline Inclusion Criteria & Exclusion Criteria \\
\hline $\begin{aligned} & \text { Population } \\
& \text { - } \text { Average age 2-18 } \\
&- \text { Refugee/AS/Internally displaced } \\
&- \text { Any gender/ethnicity/country of } \\
& \text { origin/trauma/educational status } \\
&-\quad \text { Experiencing mental health symptoms } \\
& \text { of PTSD, anxiety or depression }\end{aligned}$ & $\begin{aligned} & \text { Population } \\
& \text { - } \text { Aged }<2 />18 \\
&- \text { Studies combining target population } \\
& \text { with another population } \\
&- \text { Non-displaced individual, still exposed } \\
& \text { to war } \\
& \text { - } \text { Asymptomatic }\end{aligned}$ \\
\hline $\begin{array}{ll}\text { Intervention } \\
- & \text { CBT as treatment modality } \\
- & \text { CBT delivered in any setting } \\
- & \text { CBT delivered by any individual }\end{array}$ & $\begin{array}{l}\text { Intervention } \\
-\quad \text { Intervention not clearly described } \\
-\quad \text { CBT used in combination with another } \\
\text { therapy }\end{array}$ \\
\hline $\begin{array}{l}\text { Comparison } \\
\text { - Within-subjects or between-subjects } \\
\text { comparison } \\
\text { - } \quad \text { CBT compared to controls or other } \\
\text { therapies }\end{array}$ & $\begin{array}{l}\text { Comparison } \\
-\quad \text { No comparative measures }\end{array}$ \\
\hline $\begin{array}{l}\text { Outcomes } \\
\text { - Change in PTSD, anxiety or depression, } \\
\text { measured on a validated scale, pre and } \\
\text { post- intervention } \\
\text { - } \quad \text { Any follow up period }\end{array}$ & $\begin{array}{ll}\text { Outcomes } \\
\text { - } & \text { No validated scale used to measure } \\
& \text { symptoms } \\
- & \text { No pre and post-intervention scores } \\
\text { - } & \text { Studies using surrogate markers }\end{array}$ \\
\hline $\begin{aligned} & \text { Study Type } \\
& \text { - } \text { Randomised controlled trials } \\
&- \text { Non-randomised controlled trials } \\
&- \text { Observational studies } \\
&- \text { Case series } \\
&- \text { Case studies } \\
&- \text { Studies after } 1951 \\
&\end{aligned}$ & $\begin{array}{l}\text { Study Type } \\
-\quad \text { Systematic reviews } \\
-\quad \text { Meta-analyses }\end{array}$ \\
\hline
\end{tabular}


articles. The abstracts of 452 studies were reviewed by two authors (KL and AS), and 82 studies were eligible for fulltext screen. Full texts were screened by both authors and 16 studies were found to meet the inclusion criteria.

\section{Data Extraction}

To standardise the process, a data extraction table was created based upon the Cochrane data extraction table (38). No missing information was identified and thus contact with authors was unnecessary. Abbreviations for the outcome measures will be used from this point onwards, below in Fig. 3 is a list of the measures used.

\section{Methodological Quality}

The Cochrane collaboration recommend against the use of numerical scales to asses bias, due to the "lack of empirical evidence", instead recommending rating bias as "low" "high" or "uncertain" risk against several domains (38). Figure 4 summarises the risk of bias assessment for this review.

The nature of behavioural interventions meant most studies were subject to a high-risk of bias, including failure to randomise participation $(n=12)$, no participant/researcher blinding $(n=11)$ and lacking a control group $(n=12)$. At this point in the review, due to the heterogeneity of study designs

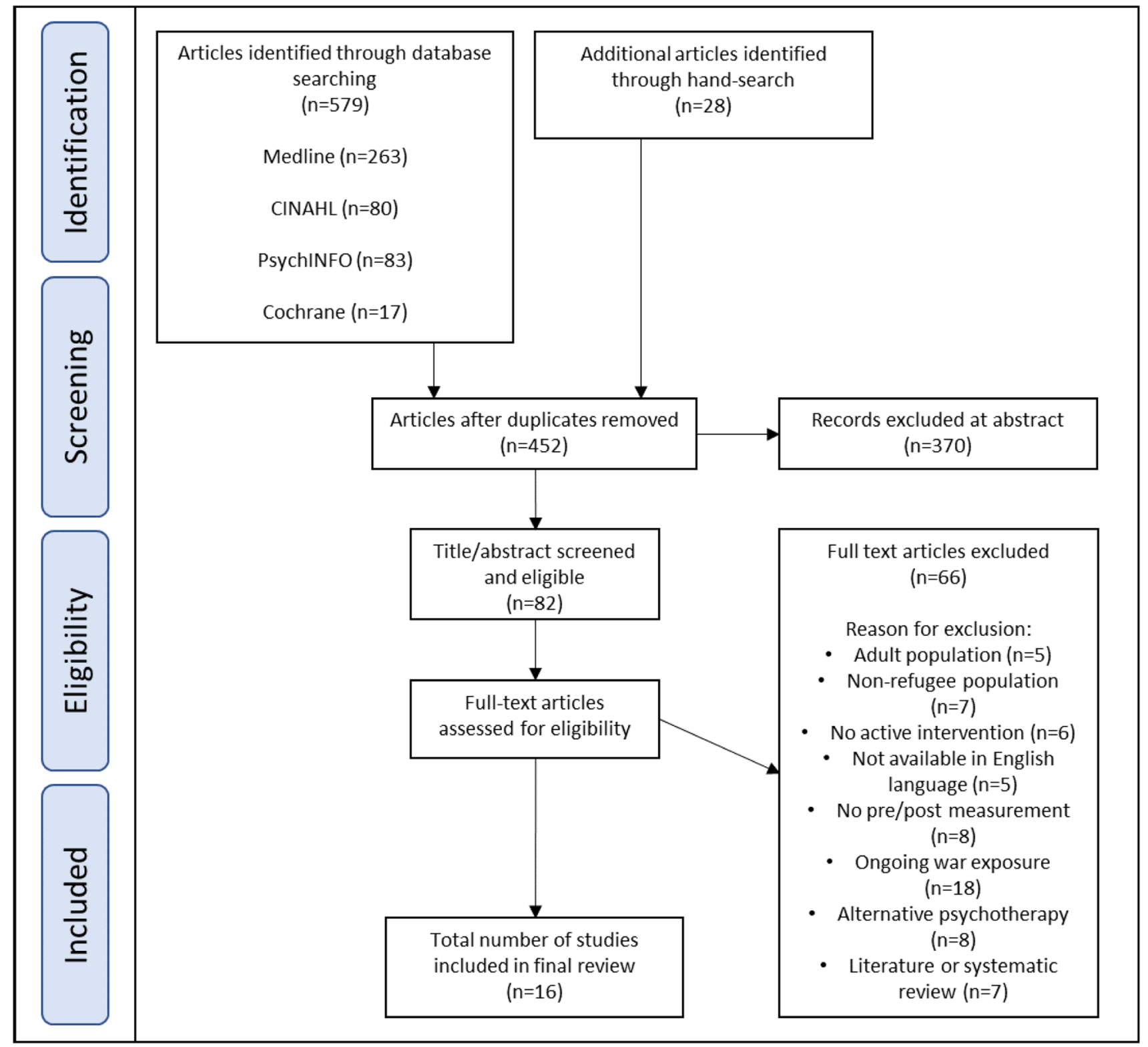

Fig. 2 PRISMA flow-diagram 
-UCLA-PTSD-The University of California at Los Angeles Post-Traumatic Stress Disorder Reaction Index for DSM-5 (Steinberg et al., 2013) -CRIES-8/13- Children's Revised Impact of Event Scale 8/13 (Smith et al., 2005)

-DSRS- Depression Self Rating Scale for Children (Birleson, 1981)

-SCAS- The Spence Children's Anxiety Scale (Spence, 1998)

-SDQ- Strengths and Difficulties Questionnaire (Goodman et al., 2000)

-RCMAS- Revised Children's Manifest Anxiety Scale (Reynolds and Richmond, 1978)

-PROPS Parent Report of Post-Traumatic Stress Symptoms (Greenwald and Rubin, 1999)

-CAPS-CA- Clinician administered PTSD scale- Child/Adolescent version (Nader et al., 1996)

-CDI- Children's Depression Inventory (Kovacs, 1985)

-SCARED- Screen for Child Anxiety Related Disorders (Birmaher et al., 1999)

-CPTS-RI-Child Post-traumatic Stress Reaction Index (Pynoos, 2002)

-PDS- Post-traumatic diagnosis scale (Foa et al., 1997)

-CATS-Child an Adolescent Trauma Scale (Sascher et al., 2017)

-AYPA- African Youth Psychosocial Assessment Instrument (Bolton et al., 2001)

-PHQ-8- Patient Health Questionaire Depression Scale (Pfizer, 2005)

-MADRS-S-Montgomery-Asberg Depression Rating Scale Self-report (Fantino and Moore., 2009)

Fig. 3 Abbreviations for outcome measures

and outcome measures and high risk of bias, meta-analysis was deemed inappropriate. Instead the decision was made to conduct a narrative synthesis.

\section{General Overview of Included Studies}

Sixteen studies of CBT on refugee children were identified for inclusion. All studies took place since the year 2000, and all were published in journals except for Tsoupas (2011) (39) which was a PHD thesis publication. All studies except for O'Callaghan et al. (2015) and Gomez et al. (2017) occurred in countries of high economic development $(40,41)$.

The study aims were to treat mental health symptoms of PTSD, anxiety or depression, with most participants having baseline symptoms classed as clinical disease. All studies had either a between-subject or within-subject comparison.

The sample sizes ranged from one participant to eightytwo participants. Most studies included children of mixed ethnicities $(39,42-48)$, four studies included only children from Africa $(33,47,49,50)$, one study included only children from Yugoslavia (51), one study included only children from Vietnam and Cambodia (52), one study included only children from Syria (41) and one study included only children from Afghanistan (53). Participants with severe mental health symptoms such as psychosis or suicidality were excluded in most studies.

Five of the studies were controlled trials $(39,42,43,51)$, two studies were randomised equivalence trials $(40,49)$, seven of the study designs were case-series whereby observations on the same group of participants are made before and after the intervention $(41,44-46,49,52,53)$ and the remaining two were case-reports $(50,54)$.
The type of CBT was predominantly trauma-focused $\mathrm{CBT}$, and the total duration of therapy ranged from six hours to twenty-eight hours. Seven of the studies used interpreters $(39,41,44,44,45,49,52)$, and in seven studies the parents/ care-givers also received therapy $(40,44-47,49,50)$.

Seven of the studies had a follow-up period $(40,42,43$, $46,49,50,52)$ which ranged from one to twelve months (Tables 1 and 2).

\section{Outcomes}

Tables 3 and 4 give the statistical outcomes of each study.

Objective 1.) To assess the effects of CBT on PTSD, anxiety and depression in child refugees/AS.

Overall, post-intervention the mental health outcome scores of PTSD, anxiety and depression were lower than the pre-intervention scores for all sixteen studies (See Table 5), suggesting a reduction in mental health symptoms following CBT. This reduction was statistically significant in twelve studies (40-48, 51-53). The Cohen's d effect sizes (where calculated) were small to large $(\mathrm{d}=0.35-1.75, \mathrm{p}<0.05)$. In eight of the studies, the post-intervention scores became subclinical, classed as a "clinically significant" change for the purposes of discussion $(40,41,44,46,47,50,51,54)$.

More specifically, the studies measuring PTSD symptoms demonstrated the greatest reduction in symptoms, with nine out of the thirteen studies demonstrating a reduction in symptoms that reached statistical significance $(\mathrm{p}<0.05)(40,41$, $43-48,53)$ and seven of the studies reaching a higher significance level of $\mathrm{p}<0.01(40,41,43,44,47,48,53)$. The symptoms became sub-clinical in seven of the studies $(40,41$, $44,46,47,50,54)$. Where Cohen's d effect sizes had been 


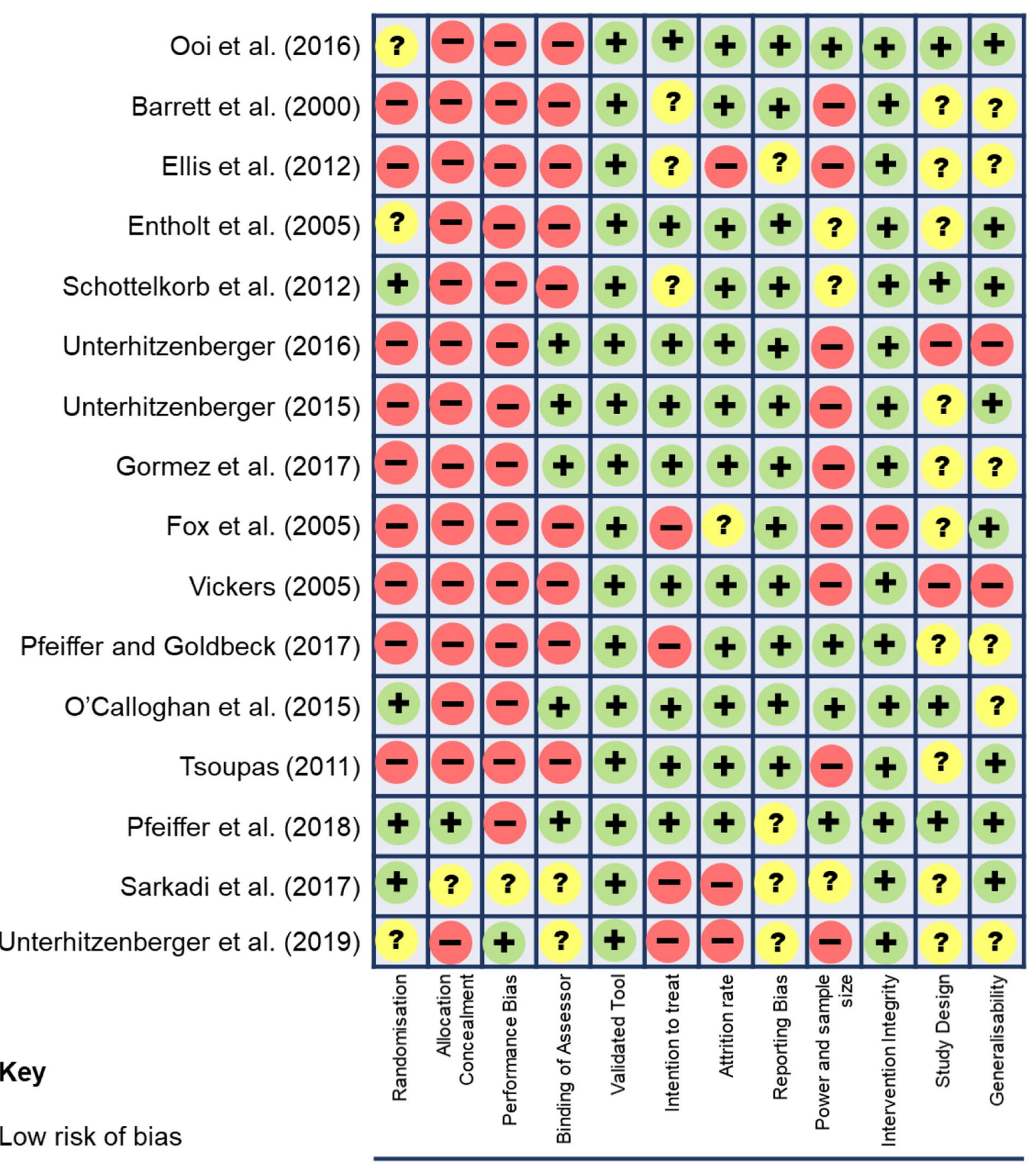

? Unclear risk of bias

High risk of bias

Fig. 4 Risk of Bias in included studies

calculated they were medium to large $(\mathrm{d}=0.61-1.75, \mathrm{p}<0.03)$ $(40,47,53)$.

Of the ten studies which included depression symptoms, six reached statistical significance $(\mathrm{p}<0.05)(40,42,45,46$,
$48,52)$ with four reaching a higher statistical significance of $\mathrm{p}<0.01(40,42,45,46)$. The symptoms became subclinical in three of the studies $(33,34,45)$. Where effect sizes were calculated they were small to medium $(f=0.15-5.20)(40,42)$. 


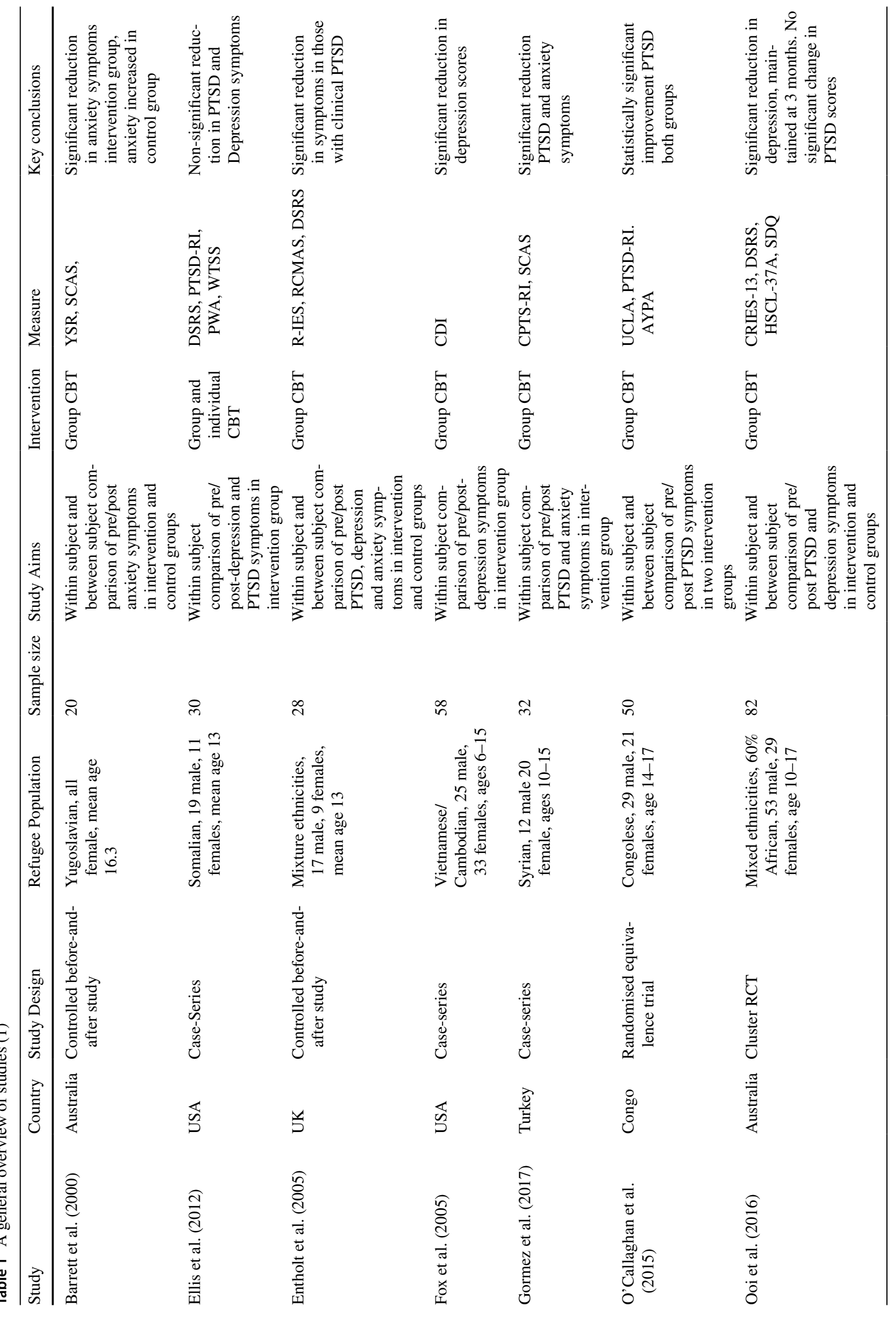




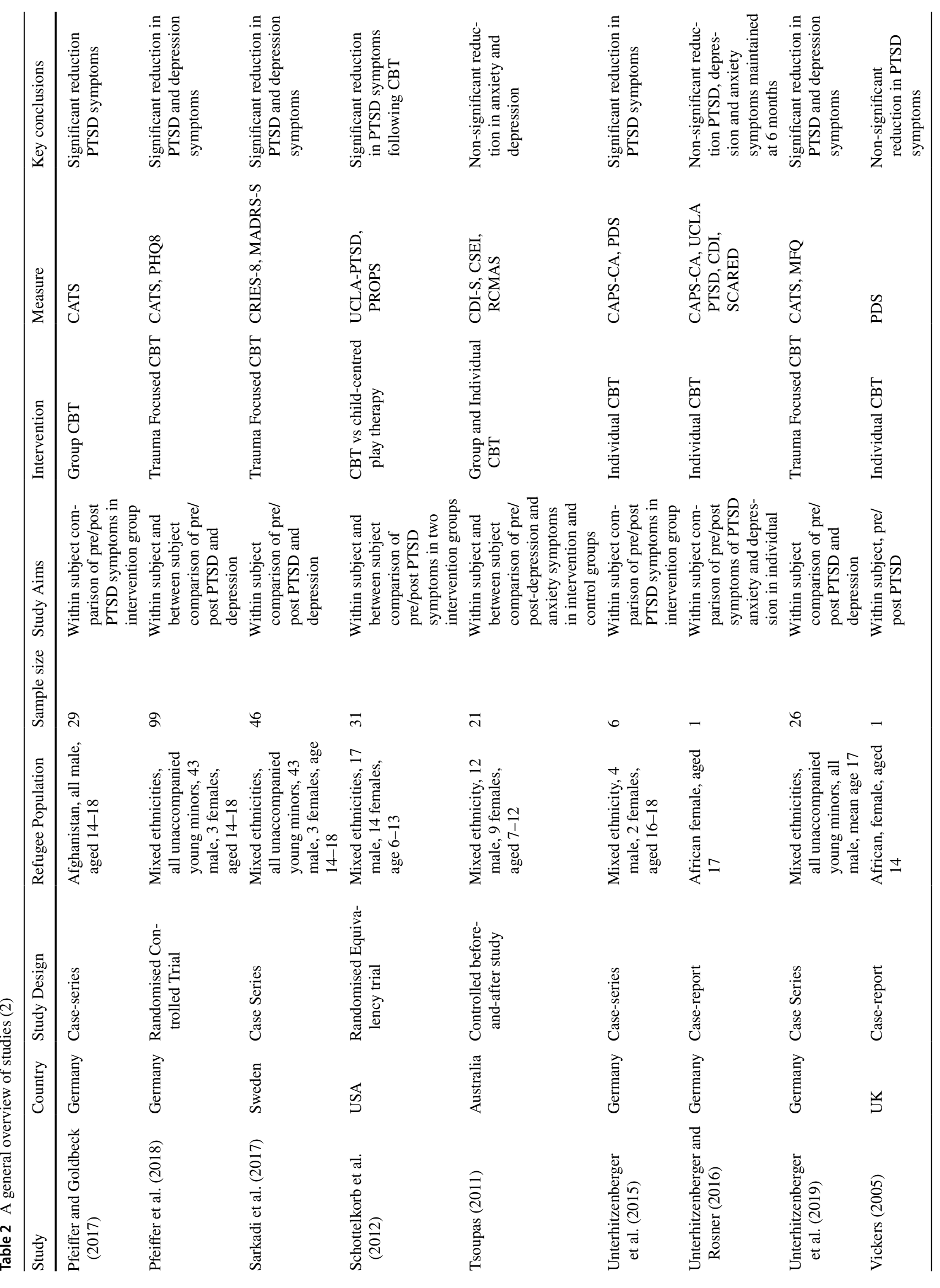


Table 3 Visual Display of Outcomes Table

\begin{tabular}{|c|c|c|c|c|c|c|c|}
\hline Study & Study Type & Study Size & Study Aim & Depression & Anxiety & PTSD & $\begin{array}{l}\text { Clinically } \\
\text { signifi- } \\
\text { cant? }\end{array}$ \\
\hline Barrett et al. (2000) & Controlled Trial & 20 & Preventative & & $\downarrow *$ & & \\
\hline Ellis et al. (2012) & Case-series & 30 & Preventative & $\downarrow$ & & $\downarrow$ & \\
\hline Entholt et al. (2005) & Controlled Trial & 28 & Preventative & $\leftrightarrow$ & $\downarrow$ & $\downarrow * *$ & \\
\hline Fox et al. (2005) & Case-Series & 58 & Preventative & $\downarrow *$ & & & \\
\hline Gormez et al. (2017) & Case-Series & 32 & Treatment & & $\downarrow * *$ & $\downarrow * *$ & \\
\hline O’Callaghan et al. (2015) & Controlled Trial & 50 & Treatment & $\downarrow * *$ & $\downarrow * *$ & $\downarrow * *$ & \\
\hline Ooi et al. (2016) & Controlled Trial & 82 & Preventative & $\downarrow * *$ & & $\downarrow$ & \\
\hline Pfeiffer et al. (2017) & Case-Series & 29 & Treatment & & & $\downarrow * *$ & \\
\hline Pfeiffer et al. (2018) & Randomised controlled trial & 50 & Treatment & $\downarrow *$ & & $\downarrow * *$ & \\
\hline Sarkadi et al. (2017) & Case Series & 46 & Treatment & $\downarrow * *$ & & $\downarrow *$ & \\
\hline Schottelkorb et al. (2012) & Controlled Trial & 31 & Treatment & & & $\downarrow * *$ & \\
\hline Tsoupas (2011) & Controlled Trial & 21 & Preventative & $\downarrow$ & $\downarrow$ & & \\
\hline Unterhitzenberger et al. (2015) & Case-Series & 6 & Treatment & & & $\downarrow * *$ & \\
\hline Unterhitzenberger and Rosner (2016) & Case-Study & 1 & Treatment & $\downarrow$ & $\downarrow$ & $\downarrow$ & \\
\hline Unterhitzenberger et al. (2019) & Case-Series & 26 & Treatment & $\downarrow * *$ & & $\downarrow *$ & \\
\hline Vickers (2005) & Case-Study & 1 & Treatme Treatment & & & $\downarrow$ & \\
\hline
\end{tabular}

In Table 5 the arrows denote the direction of change in the mental health outcome measures following CBT, with a downfacing arrow denoting a reduction in mental health symptoms. The * signifies a statistically significant result whereby $\mathrm{p} \leq 0.05$ and $* *$ signifies a statistically significant result whereby $\mathrm{p} \leq 0.01$. Where post-intervention scores became sub-clinical, this was counted as a clinically significant change

Of the six studies which included anxiety symptoms, three reached statistical significance $(\mathrm{p}<0.05)(40,41,51)$, with two reaching a higher statistical significance of $\mathrm{P}<0.01$ $(40,41)$. The symptoms became subclinical in four of the studies $(40,41,50,51)$. Where effect sizes were calculated they were small $(f=0.15)(40)$.

There were no instances of the intervention group having worse scores post intervention. In contrast, in three of the four studies with control groups the mental health scores worsened over the study period $(39,43,51)$.

In five out of seven studies with a follow up period, postintervention outcome scores were maintained (42, 46, 49, $50,52)$. This ranged from one-month to up to a year in Ellis et al. (2012) (49).

Objective 2.) To assess the accessibility and acceptability of CBT for child refugees/AS.

Toupas (2011) found participant satisfaction rates to be as high as $98.2 \%$ (39). Barrett et al. (2000) found participant ratings of $4.5 / 5$ for enjoyment and 5/5 for intervention usefulness (51). Additionally, Entholt et al. (2005) and O'shea et al. (2000) found CBT was reported an acceptable intervention to both children and their families $(43,55)$. The average participant completion rate of the CBT course was $90.8 \%$.

Eight of the studies occurred within a school setting (39, $41-43,47,49,51,52$ ) and the other eight in a community outpatient setting. Eleven of the studies carried out CBT in groups (39-43, 45, 48, 49, 51-53) and five of the studies delivered individual CBT (44, 46, 47, 50, 54). Five studies used psychology students to carry out the CBT $(39,42,43$, $47,51)$, three studies used teachers $(40,41,52)$, five used mental health workers $(44,46,49,50,54)$ and three used social workers $(45,48,53)$.

Where non-clinical mental health staff were used, training was received on how to deliver CBT. Training ranged from two to three days and staff were given a CBT session manual to improve intervention fidelity.

\section{Discussion}

Objective 1. To assess the effects of CBT on PTSD, anxiety and depression in child refugees/AS.

This is the first systematic review to focus solely on CBT outcomes in child refugee populations, with promising results. This review demonstrated a universally positive impact of CBT on symptoms of PTSD, depression and anxiety in child refugees across a broad age range, population background, setting and delivery method of CBT.

This review had a greater uniformity of positive results than previous reviews, for example when compared to the mixed positive and negative outcomes of Tyrer and Fazel (2014) (35) and Nocon et al. (2017) (37). This is potentially a consequence of having a narrower research question, for example exploring only CBT outcomes in contrast to the outcomes of a heterogenous group of interventions. These 
Table 4 Outcomes (1) (Standard deviation in brackets)

\begin{tabular}{|c|c|c|c|c|c|c|c|c|c|}
\hline Study & Measure & $\begin{array}{l}\text { CBT Pre- } \\
\text { intervention } \\
\text { mean }\end{array}$ & $\begin{array}{l}\text { CBT Post- } \\
\text { intervention } \\
\text { mean }\end{array}$ & $\begin{array}{l}\text { Statistically } \\
\text { significant? }\end{array}$ & $\begin{array}{l}\text { Control Pre- } \\
\text { intervention } \\
\text { mean }\end{array}$ & $\begin{array}{l}\text { Control } \\
\text { Post- } \\
\text { intervention } \\
\text { mean }\end{array}$ & $\begin{array}{l}\text { Statistically } \\
\text { significant? }\end{array}$ & $\begin{array}{l}\text { Clinically } \\
\text { Signifi- } \\
\text { cant? }\end{array}$ & $\begin{array}{l}\text { Follow up } \\
\text { (F/U) }\end{array}$ \\
\hline $\begin{array}{l}\text { Barrett et al. } \\
(2000)\end{array}$ & SCAS & $39.89(13.22)$ & $30.43(11.37)$ & $\begin{array}{l}\text { Yes } \\
\quad(p<0.05)\end{array}$ & $30.64(13.54)$ & $34.20(8.48)$ & No $(p>0.05)$ & $\begin{array}{l}\text { Anxiety } \\
\text { reduced } \\
\text { to sub- } \\
\text { clinical }\end{array}$ & No F/U \\
\hline $\begin{array}{l}\text { Ellis et al. } \\
\text { (2012) }\end{array}$ & $\begin{array}{l}\text { DSRS } \\
\text { UCLA- } \\
\text { PTSD }\end{array}$ & $\begin{array}{l}0.65(0.2) \\
1.01(0.49)\end{array}$ & $\begin{array}{l}0.4(0.03) \\
0.66(0.20)\end{array}$ & $\begin{array}{l}\text { No }(p>0.05) \\
\text { No }(p>0.05)\end{array}$ & & & & $\begin{array}{l}\text { Unclear } \\
\text { from } \\
\text { study }\end{array}$ & $\begin{array}{l}\text { Main- } \\
\text { tained at } \\
12 \text { months }\end{array}$ \\
\hline $\begin{array}{l}\text { Entholt et al. } \\
(2005)\end{array}$ & $\begin{array}{l}\text { CRIES-13 } \\
\text { DSRS } \\
\text { RCMAS } \\
\text { SDQ }\end{array}$ & $\begin{array}{l}39.80(8.40) \\
12.33(4.7) \\
16.87(7.22) \\
9.2(7.76)\end{array}$ & $\begin{array}{l}33.80(9.71) \\
11.67(3.62) \\
14.67(7.12) \\
5.40(4.35)\end{array}$ & $\begin{array}{l}\text { Yes } \\
\quad(p=0.01) \\
\text { No }(p=0.10) \\
\text { No }(p=0.14) \\
\text { Yes } \\
(p<0.05)\end{array}$ & $\begin{array}{l}38.55(8.37) \\
12.00(5.37) \\
16.18(6.57) \\
6.43(4.69)\end{array}$ & $\begin{array}{l}42.18(9.38) \\
13.00(6.57) \\
18.91(6.04) \\
5.43(4.28)\end{array}$ & $\begin{array}{l}\text { No }(p=0.07) \\
\text { No }(p>0.05) \\
\text { No }(p=0.07) \\
\text { No }(p>0.05)\end{array}$ & $\begin{array}{l}\text { Remained } \\
\text { clinical } \\
\text { PTSD } \\
\text { Remained } \\
\text { subclini- } \\
\text { cal anxi- } \\
\text { ety and } \\
\text { depres- } \\
\text { sion }\end{array}$ & $\begin{array}{l}\text { Not main- } \\
\text { tained at } \\
2 \text { months }\end{array}$ \\
\hline $\begin{array}{l}\text { Fox et al. } \\
\text { (2005) }\end{array}$ & CDI & $10.38(4.6)$ & $6.15(3.8)$ & $\begin{array}{l}\text { Yes } \\
\quad(p<0.05)\end{array}$ & & & & $\begin{array}{l}\text { Remained } \\
\text { sub- } \\
\text { clinical } \\
\text { depres- } \\
\text { sion }\end{array}$ & $\begin{array}{l}\text { Maintained } \\
\text { at } 1 \text { month }\end{array}$ \\
\hline $\begin{array}{l}\text { Gormez et al. } \\
\text { (2017) }\end{array}$ & $\begin{array}{l}\text { SCAS } \\
\text { CPTS-RI }\end{array}$ & $\begin{array}{l}53.28(13.78) \\
23.9(12.76)\end{array}$ & $\begin{array}{l}40.38(20.59) \\
17.6(13.64)\end{array}$ & $\begin{array}{l}\text { Yes } \\
\quad(p=0.01) \\
\text { Yes } \\
\quad(p=0.01)\end{array}$ & & & & $\begin{array}{l}\text { PTSD } \\
\text { reduced } \\
\text { to sub- } \\
\text { clinical } \\
\text { Remained } \\
\text { clinical } \\
\text { anxiety }\end{array}$ & None \\
\hline $\begin{array}{l}\text { O'Callaghan } \\
\text { et al. } \\
\text { (2015) }\end{array}$ & $\begin{array}{l}\text { UCLA- } \\
\text { PTSD } \\
\text { AYPA }\end{array}$ & $\begin{array}{l}47.77(6.62) \\
45.08(11.26)\end{array}$ & $\begin{array}{l}21.54(10.13) \\
19.08(15.09)\end{array}$ & $\begin{array}{c}\text { Yes-medium } \\
\text { effect size } \\
(\mathrm{n} 2=0.55 \\
\mathrm{p}<0.001) \\
\text { Yes- large } \\
\text { effect size } \\
(\mathrm{n} 2=0.35 \\
\mathrm{p}<0.001)\end{array}$ & $\begin{array}{l}46.59(7.93) \\
43.41(12.86)\end{array}$ & $\begin{array}{l}41.77(9.39) \\
36.05(10.3)\end{array}$ & $\begin{array}{l}\text { No } \\
\quad(p=0.057) \\
\text { Yes } \\
(p<0.05)\end{array}$ & $\begin{array}{l}\text { PTSD, } \\
\text { anxi- } \\
\text { ety and } \\
\text { depres- } \\
\text { sion } \\
\text { reduced } \\
\text { to sub- } \\
\text { clinical }\end{array}$ & $\begin{array}{l}\text { Not main- } \\
\text { tained at } \\
6 \text { months }\end{array}$ \\
\hline $\begin{array}{l}\text { Ooi et al. } \\
\text { (2016) }\end{array}$ & $\begin{array}{l}\text { DSRS } \\
\text { CRIES-13 }\end{array}$ & $\begin{array}{l}10.96(5.26) \\
23.02(10.51)\end{array}$ & $\begin{array}{l}8.68(5.48) \\
15.88(9.58)\end{array}$ & $\begin{array}{l}\text { Yes } \\
\quad(\mathrm{p}<0.001) \\
\text { Medium } \\
\quad \text { effect size } \\
\text { No }\end{array}$ & $\begin{array}{l}9.17(4.61) \\
17.92(11.86)\end{array}$ & $\begin{array}{l}8.81(4.80) \\
15.68(8.84)\end{array}$ & $\begin{array}{l}\text { No }(p<0.05) \\
\text { No }(p<0.05)\end{array}$ & $\begin{array}{l}\text { Remained } \\
\text { sub- } \\
\text { clinical } \\
\text { depres- } \\
\text { sion and } \\
\text { PTSD }\end{array}$ & $\begin{array}{l}\text { Depression } \\
\text { improve- } \\
\text { ments } \\
\text { main- } \\
\text { tained at } \\
3 \text { months }\end{array}$ \\
\hline
\end{tabular}

results support the "promising" outcomes of CBT reported in these previous reviews and answer those authors' calls for further research into CBT outcomes.

The reduction in symptoms brought children into subclinical levels of symptoms in eight of the studies. Furthermore, improvements were greatest in those with the most severe baseline symptoms (45). These findings are in line with those of Foa et al. (56); that those with the highest PTSD symptomology improved the most post-CBT. This is vitally important, given the detrimental effects of mental health symptoms on the physical health, education and acculturation on refugee children as discussed in the introduction $(12,57)$, and how prompt treatment of mental health symptoms reduces self-harm and suicide (18). This should encourage providers to include children with high symptomology in treatment programmes.

CBT was found to have greatest impact on PTSD scores compared to anxiety and depression. These findings support those of the review by Morina et al. (2017) (34) into child survivors of mass trauma, whereby CBT effect sizes were greatest for PTSD symptoms over depression and anxiety symptoms. This may be a factor of the type of CBT utilised 


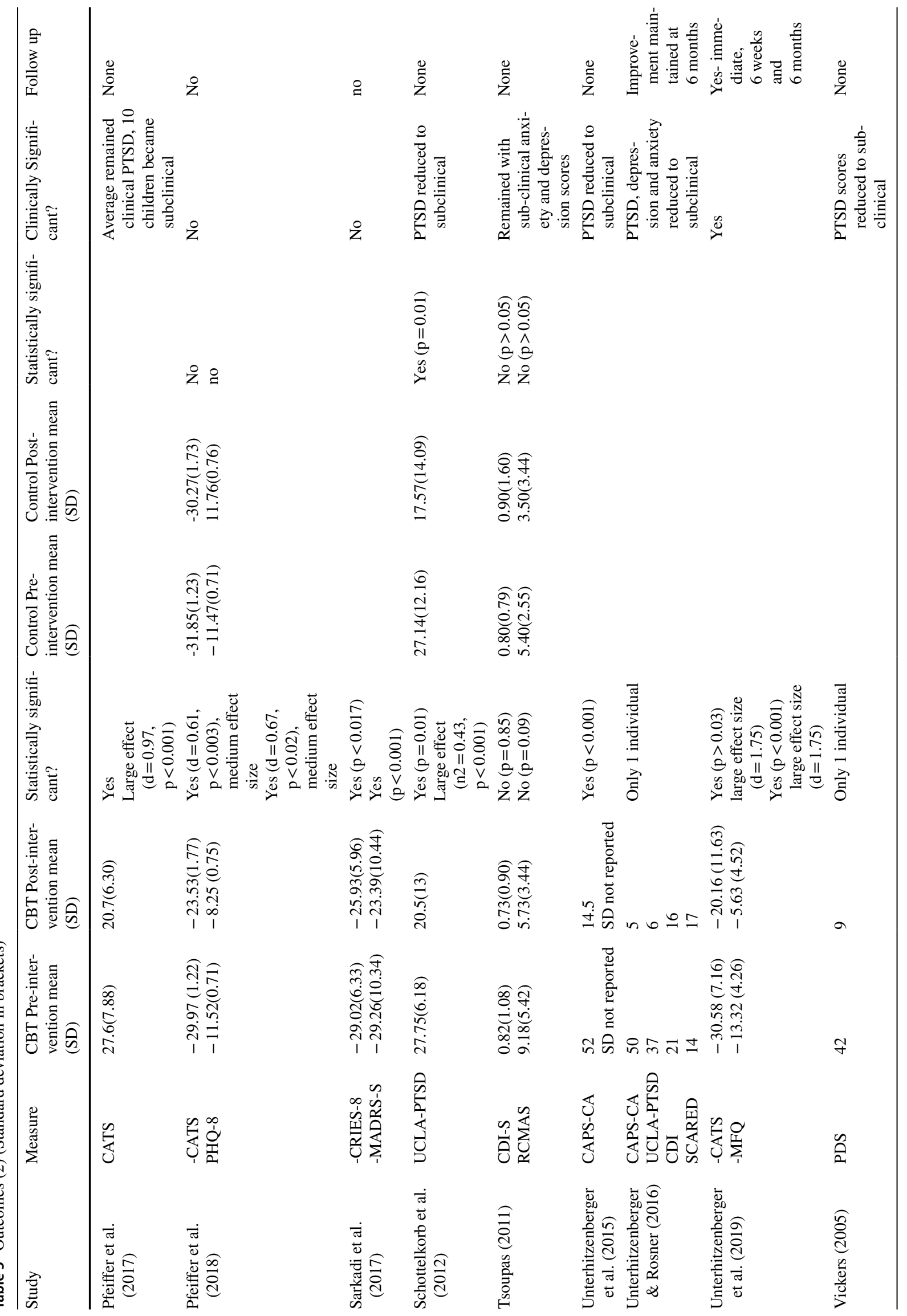


in the studies, as "trauma-focused CBT" was the most common form of CBT used across the studies. This type of CBT focuses on the adaptive processing of past-traumas and related arousal symptoms (16). Further comparative research into the outcomes of different CBT types on specific mental health symptoms would be useful.

Five out of seven studies with a follow-up period found levels of symptoms remained lower than pre-intervention scores, even up to one-year post intervention (49). This contrasts with symptoms of control groups which worsened over the follow-up period. Similar findings have been found in non-refugee children treated with CBT for PTSD following sexual abuse, whereby treatment benefits were found to be sustained at one and two year intervals $(58,59)$. This suggests that the passage of time alone is not a healing factor for these children. Indeed, in Ooi et al. (2016), post-intervention scores improved further over the follow-up period, suggesting a possible delayed intervention effect (42). A time-lapse between symptom reduction and functional improvement has also been suggested in earlier studies $(60,61)$ and merits further exploration.

The most common exclusion factor applied within the individual studies was of children with severe mental illness $(42,53)$. Arguably this excludes some of the most vulnerable in this population, and as discussed earlier potentially those most likely to benefit from CBT. The second most common exclusion was language barriers $(42,43,53)$. However, the studies with the resources to use interpreters and trained mental-health workers also reported successful outcomes in children with language barriers and severe symptoms, suggesting such children should not be excluded where possible.

Interestingly, in the two included equivalence studies, the other psychological therapies - "child friendly spaces" and "child centred play therapy" were equally as effective as CBT $(40,47)$. Therefore, it cannot be ruled out that improvements in symptoms after any psychological therapy are a factor of increased positive adult attention, rather than the specific components of each therapy.

Finally, no adverse effects of CBT were reported. There did not appear to be any evidence of "re-traumatising" following CBT or participants having difficulty understanding the concepts of CBT, concerns previously raised by Rousseau et al. and Kinzie et al. (62, 63).

Objective 2. To assess the accessibility and acceptability of CBT for child refugees/AS.

Most studies were sited in schools, and within the school-timetable for participants, making them accessible. This is in line with the World Health Organization's
(WHO) policy on delivering mental health care through community resources rather than isolated clinics (64). School settings were feasible and associated with high attendance and low attrition rates, with an average intervention completion rate of $90.8 \%$ across all studies. This is particularly important given the barriers to accessing mental health care faced by this vulnerable population (22). The success of school-based CBT at reducing symptoms concurs with the previous systematic review by Sullivan and Simonson (2016) (36).

Due to resource limitations and middle-income country settings, seven of the studies trained existing staff members such as teachers and social workers to deliver CBT. This review demonstrates that with additional training, such taskshifting can enable CBT to be delivered feasibly and accessibly in resource-poor settings. Impressively, these studies still gleaned beneficial mental health outcomes with high intervention fidelity.

Furthermore, this review additionally found that teachers were able to successfully identify and refer children struggling with clinical levels of mental health symptoms using the measurement scales. There is potential scope here to strengthen mental health referral processes from schools to specialist services.

The intervention appears acceptable to the children, as high satisfaction and enjoyment rates were reported by the four studies which specifically enquired about them.

Finally, Unterhitzenberger and Rosner (2016) demonstrated how acceptability can be further advanced by using translators as cultural-brokers, to explain cultural differences in emotions and emotional expressions to both the child and the interpreter (50), meriting further exploration.

\section{Recommendations}

This review recommends CBT for the treatment of child refuges with PTSD, depression and anxiety, although acknowledges the research base needs strengthening with more methodologically robust studies. Areas requiring further research include 1.) exploring the effects of different types of CBT on specific mental health disorders and 2.) whether subsequent CBT booster sessions help maintain positive outcomes. 


\section{Limitations}

This review has demonstrated a scarcity of primary research on this subject matter. The high risk of bias in several of the included studies should also be considered when interpreting these findings. Furthermore, a lack of language interpretation resources led to the exclusion of potentially relevant foreign-language articles.

\section{Conclusion}

This review is the first to systematically concentrate on the outcomes of CBT on child refugee/AS mental health. CBT consistently reduced symptoms of depression, anxiety and PTSD in child refugees/AS. Results were unanimously positive despite the variety of therapists and settings included. School-based services could circumvent access and financial issues experienced by this population. The training of existing key workers such as teachers and social workers CBT can be a cost-effective and sustainable intervention to help this vulnerable group of patients.

Therefore, this review cautiously recommends its use, yet acknowledges there is a dire need for more methodologically rigorous primary studies of CBT in this population.

\section{Appendix A}

\section{A: Search Strategies}

\section{Medline Search Strategy}

1 Adolescent/ or child/ or child, preschool/ $(2,829,599)$.

2 Refugees/ (8905).

3 Exp War Exposure/ (404).

4 Asylum seeker.kw. (37).

5 (Asylum adj1 seek\$3).ab,ti. (1232).

6 Refugee.ab,kw,ti. (4090).

7 (Expos\$3 adj2 war).ab,ti. (400).

8 "Displaced by war".ab,ti. (13).

9 (Internal\$2 adj1 displace\$4).ab,ti. (474).

10 (War adj2 affected).ab,ti. (236).

112 or 3 or 4 or 5 or 6 or 7 or 8 or 9 or $10(10,959)$.

12 Cognitive Therapy/ $(22,489)$.

13 Adaptation, psychological/ or exp emotional adjustment/ $(89,064)$.

14 Cognitive behavior therapy.kw. (249).

15 Cognitive therapy.kw. (225).

16 (Cognitive adj2 therap\$3).ab,ti. (14,228).

1712 or 13 or 14 or 15 or $16(113,528)$.
181 and 11 and 17 (260).

\section{Embase Search Strategy}

1 Preschool child/ or adolescent/ or child/ $(2,446,671)$.

2 Refugees/(10,687).

3 Exp War Exposure/ (186).

4 Asylum seeker.kw. (89).

5 (Asylum adj1 seek\$3).ab,ti. (1756).

6 Refugee.ab,kw,ti. (5537).

7 (Expos\$3 adj2 war).ab,ti. (526).

8 "Displaced by war".ab,ti. (13).

9 (Internal\$2 adj1 displace\$4).ab,ti. (698).

10 (War adj2 affected).ab,ti. (310).

112 or 3 or 4 or 5 or 6 or 7 or 8 or 9 or $10(13,790)$.

12 Cognitive Therapy/ $(42,674)$.

13 Psychological adjustment/ or coping behavior/ $(52,249)$.

14 Cognitive behavior therapy.kw. (1185).

15 Cognitive therapy.kw. (1526).

16 (Cognitive adj2 therap\$3).ab,ti. $(25,252)$.

1712 or 13 or 14 or 15 or $16(100,233)$.

181 and 11 and 17 (139).

\section{PsycINFO Search Strategy}

1 Refugees/ (5254).

2 Exp War Exposure/ (0).

3 Asylum seeker.kw. (0).

4 (Asylum adj1 seek\$3).ab,ti. (1289).

5 Refugee.ab,kw,ti. (4234).

6 (Expos\$3 adj2 war).ab,ti. (549).

7 "Displaced by war".ab,ti. (14).

8 (Internal\$2 adj1 displace\$4).ab,ti. (292).

9 (War adj2 affected).ab,ti. (375).

101 or 2 or 3 or 4 or 5 or 6 or 7 or 8 or $9(7812)$.

11 Cognitive Therapy/ $(13,107)$.

12 Adaptation, psychological/ or exp emotional adjustment/ $(21,001)$.

13 Cognitive behavior therapy.kw. (0).

14 Cognitive therapy.kw. (0).

15 (Cognitive adj2 therap\$3).ab,ti. (26,343).

1611 or 12 or 13 or 14 or $15(52,686)$.

17 Child.mp. $(322,109)$.

18 Children.mp. (498,343).

19 Adolescent.mp. $(153,423)$.

20 Adolescence.mp. [mp = title, abstract, heading word, table of contents, key concepts, original title, tests \& measures] $(67,089)$.

2117 or 18 or 19 or $20(741,618)$.

2210 and 16 and 21 (83). 


\section{Cochrane Search Strategy}

1 Adolescent/ or child/ or child, preschool/(122,082).

2 Refugees/ (89).

3 Exp War Exposure/ (0).

4 Asylum seeker.kw. (4).

5 (Asylum adj1 seek\$3).ab,ti. (23).

6 Refugee.ab,kw,ti. (158).

7 (Expos\$3 adj2 war).ab,ti. (29).

8 "Displaced by war".ab,ti. (1).

9 (Internal\$2 adj1 displace\$4).ab,ti. (19).
10 (War adj2 affected).ab,ti. (37).

112 or 3 or 4 or 5 or 6 or 7 or 8 or 9 or 10 (269).

12 Cognitive Therapy/ (6993).

13 Adaptation, psychological/ or exp emotional adjustment/ (3863).

14 Cognitive behavior therapy.kw. (20).

15 Cognitive therapy.kw. (2432).

16 (Cognitive adj2 therap\$3).ab,ti. (9655).

1712 or 13 or 14 or 15 or $16(16,593)$.

181 and 11 and 17 (17).

\section{CINAHL Search Strategy}

\section{CINAHL Search Strategy}


Acknowledgements Thanks to Lesley Patterson for assisting with the literature search. Thanks to James Spearing for proofreading the article.

\section{Compliance with Ethical Standards}

Conflict of interest This research did not receive any specific grant from funding agencies in the public, commercial, or not-for-profit sectors.

Open Access This article is licensed under a Creative Commons Attribution 4.0 International License, which permits use, sharing, adaptation, distribution and reproduction in any medium or format, as long as you give appropriate credit to the original author(s) and the source, provide a link to the Creative Commons licence, and indicate if changes were made. The images or other third party material in this article are included in the article's Creative Commons licence, unless indicated otherwise in a credit line to the material. If material is not included in the article's Creative Commons licence and your intended use is not permitted by statutory regulation or exceeds the permitted use, you will need to obtain permission directly from the copyright holder. To view a copy of this licence, visit http://creativecommons.org/licenses/by/4.0/.

\section{References}

1. UNHCR. Global Trends in Forced Displacement. 2019. https:// www.unhcr.org/5d08d7ee7.pdf. Accessed 23rd May 2020.

2. UN General Assembly. Convention Relating to the Status of Refugees, United Nations, Treaty Series, 189:137. 1951. https://www. refworld.org/docid/3be01b964.html. Accessed 29th January 2020.

3. Refugee Council. Who's Who, Definitions. 2019. https://www. refugeecouncil.org.uk/policy_research/the_truth_about_asylum/ the_facts_about_asylum. Accessed 10th January 2020.

4. Thomas S, Nafees B, Bhugra D. 'I was running away from death'the pre-flight experiences of unaccompanied asylum seeking children in the UK. Child Care Health Development. 2004;30:113-22.

5. Miller K, Rasmussen A. War exposure, daily stressors, and mental health in conflict and post-conflict settings: bridging the divide between trauma-focused and psychosocial frameworks. Soc Sci Med. 2010;70(1):7-16

6. Ellis BH, Lincoln AK, MacDonald HZ, Cabral H. Mental health of Somali adolescent refugees: The role of trauma, stress and perceived discrimination. J Consult Clin Psychol. 2008;76:184-93.

7. Ying Y. Strengthening intergenerational/intercultural ties in migrant families: A new intervention for parents. Journal of Community Psychology. 1999;27:89-96.

8. Lavik NJ, Hauff E, Skrondal A, Solberg O. Mental disorder among refugees and the impact of persecution and exile: Some findings from an out-patient population. Br J Psychiatry. 1996;169:726-32.

9. Lau W, Thomas T. Research into the psychological well-being of young refugees. International Psychiatry. 2008;5(3):60-2.

10. Bronstein I, Montgomery P. Psychological distress in refugee children: a systematic review. Clin Child Fam Psychol Rev. 2011;14:44-56.

11. Jakobsen M, Demott MA, Heir T. Prevalence of psychiatric disorders among unaccompanied asylum-seeking adolescents in Norway. Clin Pract Epidemiol Ment Health. 2014;10:53-8.

12. Fazel M, Stein A. The mental health of refugee children. Arch Dis Child. 2002;87:366-70.
13. Kaplan I, Stolk Y, Valibhoy M, Tucker A. Baker, J: Cognitive assessment of Refugee children: Effects of trauma and new language acquisition. Transcultural Psychiatry. 2015;53(1):81-109.

14. Kessler RC, Borges G, Walters EE. Prevalence of and Risk Factors for Lifetime Suicide Attempts in the National Comorbidity Survey. Arch Gen Psychiatry. 1999;56(7):617-26.

15. Fazel M, Stein A. Mental health of refugee children: comparative study. BMJ. 2003;327:134.

16. Mace AO, Mulheron S, Jones C, Cherian S. Educational, developmental and psychological outcomes of resettled refugee children in Western Australia: A review of School of Special Educational Needs: Medical and Mental Health input. J Paediatr Child Health. 2014;50:985-92.

17. Lincoln AK, Lazarevic V, White MT, Ellis BH. The Impact of Acculturation Style and Acculturative Hassles on the Mental Health of Somali Adolescent Refugees. J Immigr Minor Health. 2016;18(4):771-8.

18. Royal College Psychiatrists (RCP). The National Confidential Inquiry into Suicide and Safety in Mental Health. 2018. https:// www.rcpsych.ac.uk/docs/nccmh. Accessed 3rd May 2020.

19. Anstiss H, Ziaian T, Procter N, Warland J, Baghurst P. Help-seeking for Mental Health Problems in Young Refugees: A Review of the Literature with Implications for Policy, Practice, and Research. Transcultural Psychiatry. 2009;46(4):584-607.

20. Bean T, Eurelings-Bontekoe E, Mooijaart A. Factors associated with mental health service need and utilization among unaccompanied refugee adolescents. Adm Policy Ment Health. 2006;33(3):342-55.

21. Murray KE, Davidson GR, Schweitzer RD. Review of refugee mental health interventions following resettlement: best practices and recommendations. Am J Orthopsychiatry. 2010;80(4):576-85.

22. Feldman R. Primary health care for refugees and asylum seekers: A review of the literature and a framework for services. Public Health. 2006;120(9):809-16.

23. Joshi C, Russell G, Cheng IH, Kay M, Pottie K, Alston M, Smith M, Chan B, Vasi S, Lo W, Wahidi SS, Harris MF. A narrative synthesis of the impact of primary health care delivery models for refugees in resettlement countries on access, quality and coordination. International Journal for Equity in Health. 2013. https://doi. org/10.1186/1475-9276-12-88.

24. National Health Inclusion Board. Inclusive Practice. 2014. https ://www.gov.uk/government/uploads/system/uploads/attachment _data/file/305912/Inclusive_Practice.pdf. Accessed 24th December 2019.

25. Pottie K, Batista R, Mayhew M, Mota L, Grant K. Improving delivery of primary care for vulnerable migrants: Delphi consensus to prioritize innovative practice strategies. Can Fam Physician. 2014;60(1):32-40.

26. Baker, C. Mental Health Statistics for England: Prevalence, services and funding. 2018. https://researchbriefings.parliament.uk/ ResearchBriefing/Summary/SN06988\#fullreport. Accessed 10th Jan 2020.

27. Royal College Psychiatrists (RCP). Cognitive Behavioural Therapy. 2017. https://www.rcpsych.ac.uk/mental-health/treatments -and-wellbeing/cognitive-behavioural-therapy-(cbt). Accessed 3rd December 2019.

28. Cohen JA. Treating acute posttraumatic reactions in children and adolescents. Biol Psychiat. 2003;53:827-33.

29. Goenjian AK, Karayan I, Pynoos RS, Minassian D, Najarian LM, Steinberg A. Outcome of psychotherapy among early adolescents after trauma. Am J Psychiatry. 1997;154:536-42. 
30. March J. Assessment of pediatric posttraumatic stress disorder. In: Saigh P, editor. Posttraumatic stress disorder: a comprehensive text. New York: Allyn \& Bacon; 1999. p. 199-218.

31. Barron IG, Abdallah G, Patrick S. Randomized control trial of a CBT trauma recovery program in Palestinian schools. J Loss Trauma. 2013;18:306-21.

32. Layne CM, Pynoos RS, Saltzman WR, Arslanagic B, Black M, Savjak N. Trauma/grief-focused group psychotherapy: schoolbased post-war intervention with traumatized Bosnian adolescents. Group Dyn. 2001;5:277-90.

33. Qouta SR, Palosaari E, Diab M, Punamäki R-L. Intervention effectiveness among war-affected children: A cluster randomized controlled trial on improving mental health. J Trauma Stress. 2012;25(3):288-98.

34. Morina N, Koerssen R, Pollet TV. Interventions for children and adolescents with posttraumatic stress disorder: A meta-analysis of comparative outcome studies. Clin Psychol Rev. 2016;47:41-54.

35. Tyrer RA, Fazel M. School and community-based interventions for refugee and asylum seeking children: a systematic review. PLoS ONE. 2014;9:2.

36. Sullivan AL, Simonson G. A Systematic Review of School-Based Social-Emotional Interventions for Refugee and War-Traumatized Youth. Review of Educational Research. 2016;86(2):503-30.

37. Nocon A, Eberle-Sejari R, Unterhitzenberger J, Rosner R. he effectiveness of psychosocial interventions in war-traumatized refugee and internally displaced minors: systematic review and meta-analysis. European journal of psychotraumatology. 2017;8(2):1388709.

38. Higgins, J.P.T., Green, S (editors): Cochrane Handbook for Systematic Reviews of Interventions Version 5.1.0. www.handbook. cochrane.org. Accessed November 10th 2019.

39. Tsoupas, J: Improving mental health and wellbeing in recentlyarrived refugee families and children. Unpublished Thesis, RMIT University, Melbourne; 2011

40. O'Callaghan P, McMullen J, Rajerty H. Comparing a trauma focused and non-trauma focused intervention with war affected Congolese youth: a preliminary randomised trial. Intervention. 2015;13(1):28-44.

41. Gormez V, Kilic HN, Orenhul AC, Demir MN, Mert EB, Makhlouta B, Kinik K, Semerci B. Evaluation of a school-based, teacher-delivered psychological intervention group program for trauma-affected Syrian refugee children in Istanbul. Turkey Psychiatry and Clinical Psychopharmacology. 2017;27(2):125-31.

42. Ooi CS, Rooney RM, Roberts C, Kane RT, Wright B, Chatzisarantis N. The Efficacy of a Group Cognitive Behavioural Therapy for War-Affected Young Migrants Living in Australia: A Cluster Randomized Controlled Trial. Frontiers in Psychology. 2016;7:1641.

43. Entholt KA, Smith PA, Yule W. School-based Cognitive-Behavioural Therapy Group Intervention for Refugee Children who have Experienced War-related Trauma. Clinical Child Psychology and Psychiatry. 2005;10(2):235-50.

44. Unterhitzenberger J, Eberle-Sejari R, Rassenhofer M, Sukale T. Rosner, R, Goldbeck, L: Trauma-focused cognitive behavioural therapy with unaccompanied refugee minors: a case series. BMC Psychiatry. 2015; 15:260.

45. Sarkadi A, Ådahl K, Stenvall E. Teaching Recovery Techniques: evaluation of a group intervention for unaccompanied refugee minors with symptoms of PTSD in Sweden. Eur Child Adolesc Psychiatry. 2018;27(4):467-79.

46. Unterhitzenberger J, Wintersohl S, Lang M. Providing manualized individual trauma-focused CBT to unaccompanied refugee minors with uncertain residence status: a pilot study. Child Adolesc Psychiatry Ment Health. 2019;13:22.
47. Schottelkorb AA, Doumas DM, Garcia R. Treatment for Childhood Refugee Trauma: A Randomized, Controlled Trial. International Journal of Play Therapy. 2012;21(2):57-73.

48. Pfeiffer E, Sachser C, Rohlmann F, Goldbeck L. Effectiveness of a trauma-focused group intervention for young refugees: a randomized controlled trial. J Child Psychol Psychiatry. 2018;59(11):1171-9.

49. Ellis HE, Miller AB, Barrett C, Abdi S, Blood EA. Multi-Tier Mental Health Program for Refugee Youth. J Consult Clin Psychol. 2012;81(1):129-40.

50. Unterhitzenberger J. Rosner, R: Case report: manualized traumafocused cognitive behavioural theray with an unaccompanied refugee minor girl. European Journal of Psychotraumatology. 2016;7:29246.

51. Barrett PM, Moore AF, Sonderegger R. The FRIENDS program for young Former- Yugoslavian refugees in Australia: A pilot study. Behaviour Change. 2000;17(3):124-33.

52. Fox PG, Rossetti J, Burns KR. Southeast Asian Refugee Children: A School-Based Mental Health Intervention. The International Journal of Psychiatric nursing research. 2005;11(1):1227-36.

53. Pfeiffer E, Goldbeck L. Evaluation of a Trauma-Focused Group Intervention for Unaccompanied Young Refugees: A Pilot Study. J Trauma Stress. 2017;30:521-36.

54. Vickers B. Cognitive Model of the Maintenance and Treatment of Post-traumatic Stress Disorder Applied to Children and Adolescents. Clinical Child Psychology and Psychiatry. 2005;10(2):217-34.

55. O'Shea B, Hodes M, Down G, Bramley J. A School-based Mental Health Service for Refugee Children. Clinical Child Psychology and Psychiatry. 2000;5(2):1359-1045.

56. Foa EB, Riggs DS, Massie ED, Yarczower M. The impact of fear activation and anger on the efficacy of exposure treatment for posttraumatic stress disorder. Behav Ther. 1995;26:487-99.

57. Rethink Mental Illness. Post-Traumatic Stress Disorder Factsheet. 2019. https://www.rethink.org/advice-and-information/about -mental-illness/learn-more-about-conditions/post-traumatic-stres s-disorder-ptsd/?gclid=EAIaIQobChMI_oeF45O06QIVW-ztCh2 m_w1WEAAYASAAEgKnNfD_BwE. Accessed 14th May 2020.

58. Cohen JA, Mannarino AP, Knudsen K. Treating sexually abused children: 1 year follow-up of a randomized controlled trial. Journal of Child Abuse and Neglect. 2005;29:135-45.

59. Deblinger E, Steer RA, Lippmann J. Two-year follow-up study of cognitive behavioural therapy for sexually abused children suffering post-traumatic stress symptoms. Child Abuse Negl. 1999;23(12):1371-8.

60. Kazdin AE, Holland L, Crowley M. Family experience of barriers to treatment and premature termination from child therapy. $\mathbf{J}$ Consult Clin Psychol. 1997;65:453-63.

61. Bolton P. Cross-cultural validity and reliability testing of a standard psychiatric assessment instrument without a gold standard. Journal of Nervous and Mental Disease. 2001;189(4):238-42.

62. Rousseau C. The mental health of refugee children. Transcultural Psychiatric Review. 1995;32:299-331.

63. Kinzie JD, Cheng K, Tsai J, Riley C. Traumatized refugee children: The case for individualized diagnosis and treatment. Journal of Nervous and Mental Disease. 2006;194:534-7.

64. World Health Organisation (WHO). Organisation of Services for Mental Health. 2003. https://www.who.int/mental_health/policy/ services/4_organisation\%20services_WEB_07.pdf. Accessed 7th January 2020.

Publisher's Note Springer Nature remains neutral with regard to jurisdictional claims in published maps and institutional affiliations. 